\title{
INTERFERÊNCIA NA COMPRA PUBLICITARIA EM TV ABERTA: ESTUDO DE CASO TV DIÁRIO
}

\author{
Interference in advertising purchase on open tv: Diário Tv case study \\ Interferencia en la compra de publicidad en tv abierta: caso de estudio Tv \\ Diário
}

Lucinda Maria Martins Tavares Gestora Comercial, professora universitária da UNIFOR - Universidade de Fortaleza lindatavares@unifor.br

\section{Resumo}

A TV aberta é um dos meios mais comercializados no Brasil, entretanto a TV Diário tem dificuldades na venda de seus espaços publicitários. Este estudo tem como tema a compra de mídia em TV Aberta em Fortaleza tendo como foco do estudo a TV Diário e na perspectiva do cliente anunciante identificar e analisar, a partir do modelo de Tamanaha (2011), quais fatores interferem na compra de espaços publicitários na TV Diário. Para realizar o desenvolvimento estudou-se os aspectos econômicos da propaganda comercial, as características dos meios de comunicação, o processo de compra de mídia na TV aberta, mídia regional e convergência digital. Foram utilizadas abordagens quantitativas e qualitativas. Os resultados encontrados mostram a relevância da TV Aberta para os anunciantes de Fortaleza e a necessidade da TV Diário se adequar ao perfil do anunciante do mercado onde atua.

Palavras-chave: Mídia. TV aberta.TV Diário.

\begin{abstract}
Open TV is one of the most commercialized media in Brazil, however TV Diário has difficulties in selling its advertising spaces. This study has as its theme the purchase of media on Open TV in Fortaleza and from the perspective of the advertising client to identify and analyze, based on the model of Tamanaha (2011), which factors interfere in the purchase of advertising spaces on TV Diário. To carry out the development, we studied the economic aspects of commercial advertising, the characteristics of the media, the process of buying media on open TV, regional media and digital convergence. Quantitative and qualitative approaches were used. The results found show the relevance of Open TV for advertisers in Fortaleza and the need for TV Diário to adapt to the profile of the advertiser in the market where it operates.
\end{abstract}

Keywords: Media. Broadcast television.TV Diário. 


\section{Resumen}

Open TV es uno de los medios más comercializados en Brasil, sin embargo TV Diário tiene dificultades para vender sus espacios publicitarios. Este estudio tiene como tema la compra de medios en TV Abierta en Fortaleza y desde la perspectiva del cliente publicitario identificar y analizar, con base en el modelo de Tamanaha (2011), qué factores interfieren en la compra de espacios publicitarios en TV Diário. Para llevar a cabo el desarrollo, se estudiaron los aspectos económicos de la publicidad comercial, las características de los medios, el proceso de compra de medios en TV abierta, los medios regionales y la convergencia digital. Se utilizaron enfoques cuantitativos y cualitativos. Los resultados encontrados muestran la relevancia de Open TV para los anunciantes en Fortaleza y la necesidad de que TV Diário se adapte al perfil del anunciante en el mercado donde opera.

Palabras clave: Medios. Televisión abierta. TV Diário.

\section{INTRODUÇÃO}

O negócio da comunicação vive um momento de grande transformação em decorrência de vários fatores como a convergência digital, a fragmentação da audiência com uma maior oferta de conteúdo e a forte concorrência direta e indireta por plataformas alternativas de mídia cada vez mais expressivas. Jenkins (2009) fala que no mundo da convergência das mídias, toda história importante é contada, toda marca é vendida e todo consumidor é cortejado por múltiplos suportes de mídia

Segundo Tamanaha (2011) nos últimos anos houve uma nova ordem na relevância dos meios de comunicação, saímos do meio impresso para os meios eletrônicos (que tem a característica de chegar a uma grande quantidade de receptores ao mesmo tempo, partindo de um único emissor) e estamos num processo de adaptação dos meios de comunicação com a presença da internet.

O grande propulsor da geração de receitas da comunicação é a venda dos espaços de propagandas, os quais as empresas utilizam estrategicamente para divulgar seus produtos e serviços com o intuito de atingirem seus objetivos de marketing. As grandes receitas publicitárias começam a ser mais diluídas em várias plataformas de comunicação com o objetivo de aumentar o contato com o público foco da comunicação.

Diante da identificação dos fatores que interferem na compra de propaganda nos meios de comunicação essa pesquisa pretende identificar e analisar quais desses fatores são essenciais para o anunciante que compra Tv Aberta em Fortaleza.

Nesse artigo foi realizado um estudo de caso da TV Diário, que é uma TV Aberta situada na cidade de Fortaleza. 
A razão da escolha se deu por ser uma empresa totalmente cearense, com ampla capacidade de geração de emprego e desenvolvimento de profissionais na área de comunicação, nas mais diversas formas de atuação, como jornalistas, produtores, artistas, dançarinas, cinegrafistas e ainda executivos de venda e marketing.

Diante dessas informações iniciais surgiu a necessidade da pesquisa para identificar e analisar o que faz com que um anunciante escolha a TV Diário para anunciar. Quais os pontos mais relevantes, sob o prisma do cliente anunciante e não anunciante, para que a TV Diário seja mais eficiente em suas estratégias comerciais?

\section{O CENÁRIO DA TV ABERTA NO BRASIL}

Segundo Sissors e Bumba (2001) os meios de comunicação são as categorias das mídias, um grupo de transportadores de informação e um veículo de comunicação é um representante desses grupos, normalmente as empresas que representam esses meios.

A TV Aberta segundo Tamanaha (2011) é um meio de grande alcance e de muito penetração em todas as camadas sociais da sociedade brasileira e está presente em 94,7\% dos lares brasileiros. A figura 1 a seguir mostra o perfil do telespectador brasileiro.

Figura 1 - Perfil do telespectador brasileiro

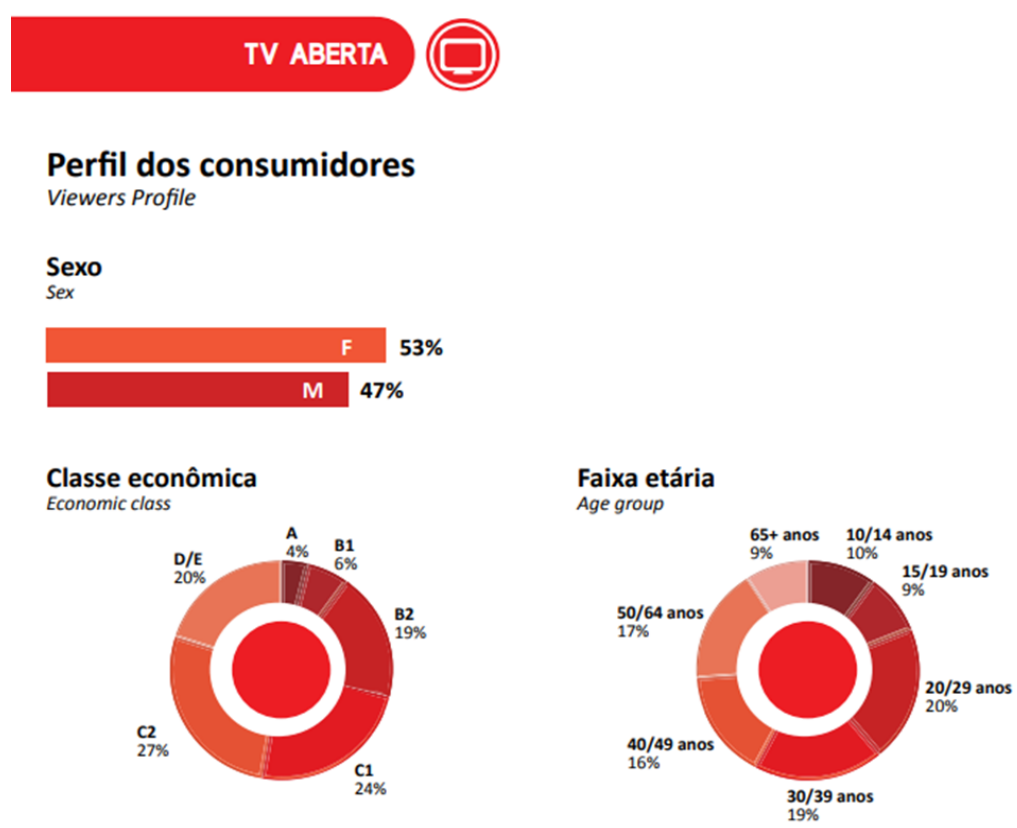

Fonte: Mídia Dados (2018).

Segundo a Pesquisa Brasileira de Mídia 2016, os brasileiros assistem cerca de 3 horas e 21 minutos de segunda a sexta e 3 horas e 39 minutos nos finais de semana, ainda mostra que a televisão permanece como meio de comunicação de maior utilização para as pessoas se 
informarem no Brasil. Praticamente nove de cada dez entrevistados fizeram menção em primeiro ou segundo lugar à TV como o veículo preferido para obter informações.

Lupetti (2014) aponta dentre seus atributos mais eficientes a associação de som, imagem e movimento que consegue levar a mensagem aos consumidores de maneira mais efetiva. Segundo Wolff (2015) o grande trunfo da TV Aberta é o esporte, o ambiente onde reina absoluta e tem grande força com a compra de direito de transmissões de várias modalidades esportivas e que os telespectadores querem assistir ao vivo. Apesar dos números favoráveis de audiência e faturamento da TV aberta, e em especial no Brasil, alguns autores apontam outras tendências para esse meio de massa como Jaffe (2008), que a partir do poder de escolha que os consumidores têm para ver, ler, ouvir e interagir com mais de 40 mil produtos de conteúdo a TV está em total declínio. Segundo Kotler, Kartajaya e Setiawan (2017) o conteúdo é novo anúncio e \# é o novo slogan.

\subsection{FATORES QUE INTERFEREM NA COMPRA DE MÍDIA}

Segundo Tamanaha (2011) temos os seguintes fatores que determinam uma compra de mídia no Quadro 1:

Quadro 1 - Fatores que interferem na compra de mídia

\begin{tabular}{|c|c|c|}
\hline AUTOR & FATOR & DESCRIÇÃO \\
\hline \multirow{5}{*}{ TAMANAHA (2011) } & Características intrisicas do meio & $\begin{array}{l}\text { Observando o ponto de vista do público e do } \\
\text { profissional de mídia, como regionalização da } \\
\text { mídia, posicionamento no mercado do veículo, } \\
\text { interferência de outras plataformas de mídia. }\end{array}$ \\
\hline & Condições especiais de compra & $\begin{array}{l}\text { Como permutas ( troca de mídia por produto ou } \\
\text { serviço), Bonificação por volume de compra ou } \\
\text { prazo de pagamento diferenciado. }\end{array}$ \\
\hline & $\begin{array}{l}\text { Formatação de veiculação } \\
\text { diferenciada em TV }\end{array}$ & $\begin{array}{l}\text { Possibilidade de ações com formatos diferentes } \\
\text { do tradicional } 30 " .\end{array}$ \\
\hline & Negociação com dados técnicos & $\begin{array}{l}\text { Usada geralmente para mídia eletrônica e } \\
\text { baseada em CPM e GRP, adequando volume de } \\
\text { mídia e investimento disponível. }\end{array}$ \\
\hline & $\begin{array}{l}\text { Relacionamento com veículos de } \\
\text { comunicação }\end{array}$ & $\begin{array}{l}\text { Através dos agenciadores de mídia e pelo qual } \\
\text { recebe-se informações sobre atualização de } \\
\text { oportunidades de mídia, bem como melhor } \\
\text { performance em negociações. }\end{array}$ \\
\hline
\end{tabular}

Fonte: Elaborado pela autora (2018).

As características de um meio contribuem para o processo de venda de mídia de cada um deles. No caso da TV Aberta o modelo brasileiro, com grande alcance nacional é um 
ponto relevante. A população tem acesso gratuito aos canais abertos e ao sinal digital que vem tomando o lugar do sinal analógico.

Um dos momentos mais importante para a comercialização dos espaços publicitários na TV Aberta foi o intervalo comercial, que segundo Demarchi (2017) foi instituído em 1962 com o Código Brasileiro de Telecomunicações, com a Lei no 4.117 e que no art. 124 definia o percentual máximo para veiculação de propaganda, que não pode exceder $25 \%$ do conteúdo de um veículo de comunicação. Na década de 70 o profissional Walter Clark da Rede Globo desenhou um modelo de comercialização, que Tamanaha (2011) aponta como o conceito inovador de grade de programação, usando a lógica dos jornais impressos com assuntos específicos.

\subsection{O PROCESSO DE VENDA DA TV ABERTA}

O modelo de negócio da TV brasileira é baseado nas grandes redes e os anunciantes têm na compra de mídia para todo o território do Brasil uma facilidade de operação de planejamento de mídia, bem como para as afiliadas que distribuem esses conteúdos e são remuneradas como uma sociedade.

Além da compra nacional os anunciantes podem fazer compras regionais e dentro da cobertura geográfica que tem interesse. A força das emissoras de rede deixa as TV’s locais extremamente frágeis comercialmente, pois não dividem cobertura ampla e nem os custos de produção dos conteúdos.

Segundo o Código Brasileiro de Telecomunicações, a Lei $\mathrm{n}^{\circ} 4.117$, que regula as concessões de rádio e TV no Brasil, permite que as principais emissoras, como a Rede Globo, a Record e o SBT, tenham contratos como cabeças-de-rede e suas afiliadas.

A venda de mídia de TV, por seu alto investimento, é cercada de práticas para se ter a maior efetividade de resultado no valor veiculado. Baseado em Tamanaha (2011), iremos a seguir listar as seguintes atividades mais usuais na compra de mídia: A mídia técnica, que é usada para conhecer públicos, alcance, frequência ideal e contribui para uma negociação otimizada; formatos diferenciados e o atendimento comercial.

O insumo básico para as ferramentas da mídia técnica são as pesquisas de mídia. Os institutos de pesquisa de mídia no Brasil, que oferecem pesquisas regulares, são o Kantar IBOPE e o IPSOS Marplan, a partir de softwares e banco de dados as informações sobre mídia e consumo de mídia são analisadas com os usos das ferramentas da mídia técnica. 
As técnicas mais usadas são: Custo por Mil (CPM), Gross Rating Point (GRP), análise do perfil de audiência e etc. A seguir veremos alguns conceitos:

1.O CPM é uma ferramenta de medição de rentabilidade e comparação, onde avaliamos o custo por cada 1000 pessoas atingidas pela comunicação. Seu cálculo segundo Tamanaha (2011) é o seguinte: o custo da inserção x 1000 dividido pela audiência absoluta (em números reais) de um determinado programa. É usada para comparar programas similares e verificar a rentabilidade financeira.

2.O GRP mede a intensidade da mídia, essa ferramenta é calculada multiplicando a audiência (percentual) de um determinado programa pela quantidade de inserções programadas (a frequência). Segundo Kotler (2000) é importante ao fazer um planejamento de comunicação ter os objetivos definidos, que podem ser persuadir, lembrar e informar. E de acordo com as necessidades e recursos financeiros intensifica a mídia pelo aumento de frequência nas veiculações.

3.O perfil da audiência são as características do público que assiste determinado programa, por meio das informações sobre o sexo, idade e classe social. Como exemplo na figura 2 a seguir o perfil da TV Diário.

Figura 2 - Perfil geral da TV Diário

\section{PERFIL GERAL DA TV DIÁRIO 1. LUGAR EM PRODUÇĀO LOCAL}
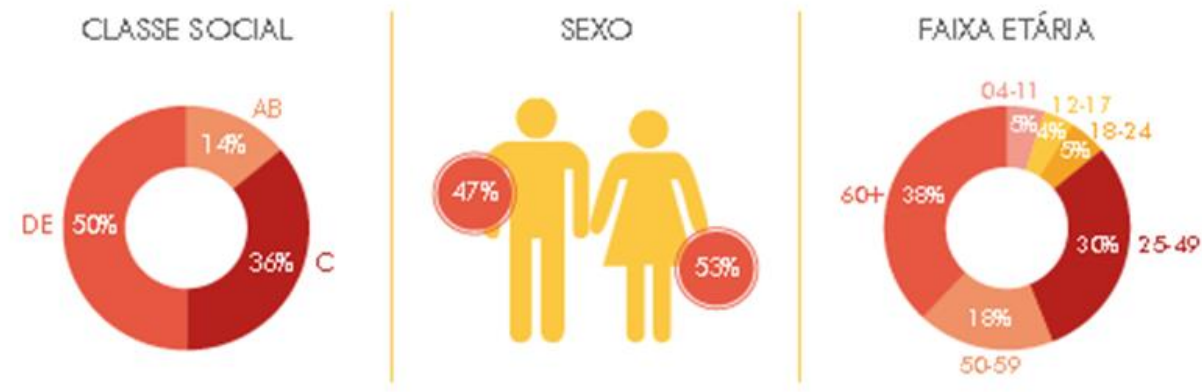

FONTE DOA DGDOS KANTARIEOPE, OUTUEROOIY

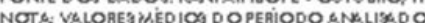

Em Fortaleza, segundo a ACERT temos as seguintes emissoras: TV Verdes Mares (afiliada Globo), TV Jangadeiro (afiliada SBT), TV Cidade (afiliada Record), NordesTV (afiliada Band), TV O Povo (afiliada Futura), TV Ceará (afiliada TV Brasil/TV Cultura), Rede TV , TV Diário, TV Fortaleza (da Câmara Municipal de Fortaleza), TV Assembleia (da 
Assembleia legislativa do Ceará) e Canal 54. A seguir a Tabela 1 com o cenário geral de audiência de TV Aberta no mercado de Fortaleza.

Tabela 1 - Cenário geral de audiência de TV Aberta no mercado de Fortaleza

\begin{tabular}{|c|c|c|c|}
\hline & \multicolumn{3}{|l|}{ Live } \\
\hline & \multicolumn{3}{|l|}{ Dezembro 2017} \\
\hline & Rat\% \{Ponderada\} & Shr\% \{Org\} & Cov\% $\{$ Soma $\}$ \\
\hline \multicolumn{4}{|l|}{ 07:00:00 - 24:00:00 } \\
\hline Total Ligados Especial & 37,82 & 100,00 & 100,00 \\
\hline TV Diario (IND) & 1,50 & 3,98 & 77,32 \\
\hline NORDESTV (BAN) & 1,35 & 3,57 & 86,02 \\
\hline Cidade Fortaleza (REC) & 4,55 & 12,03 & 93,37 \\
\hline Jangadeiro (SBT) & 7,56 & 20,00 & 96,59 \\
\hline Verdes Mares (GLO) & 14,54 & 38,46 & 98,80 \\
\hline TV Ceará (RPT) & 0,32 & 0,86 & 67,07 \\
\hline Rede TV! & 0,29 & 0,77 & 65,24 \\
\hline OCA & 2,29 & 6,05 & 95,26 \\
\hline Canais Pagos & 5,58 & 14,75 & 57,67 \\
\hline
\end{tabular}

Fonte dos dados: Kantar IBOPE Media

Datas: 01 a 31.12.2017

Universo: Para região [For] [Bom]Universo 3492.1; Amostra 758 ( 100.00\%)

Fonte: TV Diário (2018).

Os formatos mais usados são: Patrocínio de programas e de eventos, nessa modalidade de mídia o anunciante assina por intermédio de vinheta de 5" no começo e fím de um programa; comerciais de 30" nos intervalos comerciais, esse é o formato mais utilizado e a programação é escolhida de acordo com o perfil do programa, a necessidade do anunciante e sua disponibilidade financeira; Merchandising, esse termo é usado pela TV Aberta para ações diferenciadas e dentro do conteúdo, seja uma novela, programa de auditório ou programa de variedades. O Formato deve ser acertado antecipadamente com a área comercial do veículo para definição de tempo, forma e valor financeiro; Branded Content, esse novo formato é geralmente desenvolvido com a participação do cliente, agência e veículo de comunicação. É um formato que permite conteúdo relacionado com o produto do cliente de forma subliminar.

O CENP define o atendimento comercial como: "Agenciador de Propaganda: é a pessoa física registrada e remunerada pelo Veículo, sujeita à sua disciplina e hierarquia, com a função de intermediar a venda de espaço/tempo publicitário".

Os agenciadores de propaganda representam veículos de todo Brasil e suas regionais, quer seja, redes nacionais, afiliadas ou TV's locais.

Shaver (2002) aponta que os agenciadores de propaganda precisam entregar aos anunciantes: a) Valor - os anunciantes não querem o valor mais barato e sim valor adequado para seu investimento financeiro e cabe ao agenciador garantir que é isso que se está 
oferecendo; b) Serviços - os anunciantes querem contar com você quando necessário, esse é um negócio de relacionamento; c) Boas informações - Os anunciantes querem informações sobre o veículo que pretende comprar, dados, audiência, números do mercado e informações sobre a concorrência.

\subsection{A TV ABERTA E A INTERNET}

Dentro do ambiente de comercialização da TV Aberta, seja rede, afiliada ou local, o ambiente digital tem sido um grande motivo de estudo e acompanhamento do impacto em sua plataforma tradicional.

O Centro Regional de Estudos para o Desenvolvimento da Sociedade da Informação (Cetic.br), pesquisou os dados de indicadores domiciliares de 2017: No Nordeste 40\% dos domicílios tem acesso à internet, com predominância das classes A e B, 43\% dos domicílios acham desnecessário o acesso à internet, $43 \%$ não tem interesse, 32\% tem acesso em outro lugar e $60 \%$ desses domicílios estão em áreas urbanas.

A seguir a Figura 3 com o perfil do internauta brasileiro e a participação de Fortaleza nos acessos.

Figura 3 - Perfil do internauta brasileiro: acesso à internet nos últimos 30 dias

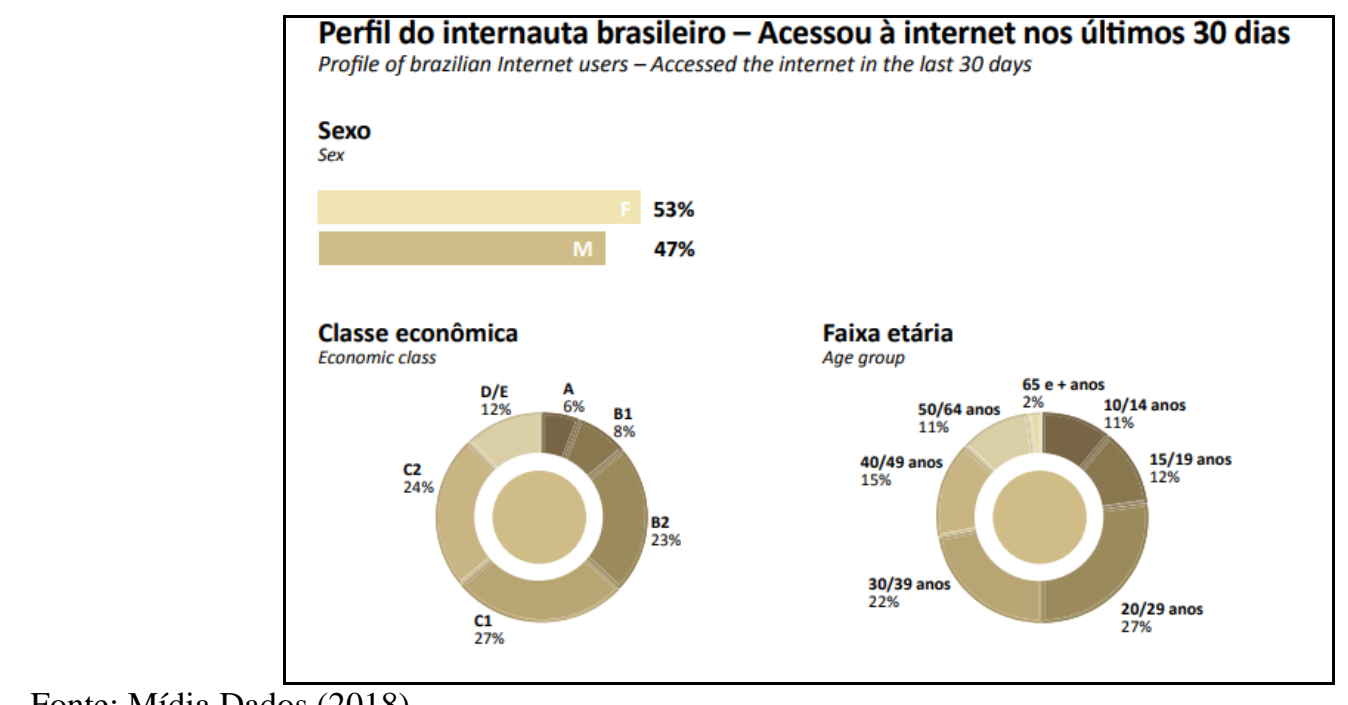

Fonte: Mídia Dados (2018).

No conceito de Jenkins (2009) a convergência é mais que uma mudança tecnológica, pois altera o relacionamento entre tecnologias existentes, indústrias, mercados, gêneros e públicos. $\mathrm{O}$ autor coloca que as mudanças que ocorrem dizem respeito as tecnologias de distribuição e que os meios de comunicação são sistemas culturais. 
De acordo com Smith (2011), o consumidor também pode receber um forte impacto sobre a venda e posicionamento de produtos, por meio de informações disponibilizadas em canais como redes sociais e blogs, pois há uma tendência crescente para que os consumidores confiem mais nas opiniões de outros consumidores à empresa que gera a informação.

Uma pesquisa realizada pela Kantar IBOPE Media, fevereiro de 2016, apontou quais as preferências e os perfis dos consumidores de mídia presentes no Brasil, de acordo com o levantamento realizado, a televisão é o meio de comunicação que possui a maior penetração, no que se refere ao consumo, se comparado com os demais. Para $37 \%$ das pessoas entrevistadas, o momento de se assistir televisão ocorre simultaneamente ao de se utilizar a internet. As preferências dos brasileiros são: noticiários, novelas e filmes. As propagandas são de grande importância para $61 \%$ dos entrevistados, pois além de possuírem caráter informativo, constituem uma forma de se suscitar o diálogo entre as pessoas. A maior parte dos telespectadores é constituída por mulheres, sendo 53\% na TV aberta e 51\% na paga.

Canatta (2014) afirma que as tecnologias digitais e da internet móvel permitiu uma experiência combinada com a televisão que voltou a valorizar a programação da TV e o assistir no momento da transmissão. $\mathrm{O}$ autor faz alusão a segunda tela (dispositivo qualquer conectado à internet e utilizado simultaneamente à televisão, numa navegação influenciada pela programação) como um instrumento de integração entre os telespectadores e grupos que ele queira interagir, sem fronteiras geográficas.

\section{A PESQUISA}

Segundo Honório e Moreno (2015) TV Diário iniciou suas atividades em 01 de julho de 1998, dentre as emissoras de TV aberta no Brasil é uma rede de televisão brasileira sediada em Fortaleza-CE. A emissora pertencente ao Sistema Verdes Mares, divisão do Grupo Edson Queiroz que controla vários veículos de comunicação em todo o país. O nome da emissora é uma homenagem ao jornal Diário do Nordeste, que também pertence ao grupo. A emissora se destaca por trazer uma programação quase na sua totalidade local, com programas e noticiários voltados para a Região Nordeste, especialmente o estado do Ceará, onde está sediada a emissora.

A emissora ficou conhecida na década de 2000, quando passou a transmitir seu sinal via satélite para todo o país, o que a fez ganhar várias afiliadas e retransmissoras e gerar uma rápida expansão, chegando a ameaçar a audiência das grandes redes de TV brasileiras, em sua maioria baseadas no Eixo Rio-São Paulo, até ter seu sinal codificado em 2009. Atualmente, a 
emissora transmite seu sinal aberto para todo estado do Ceará, para todo o país por intermédio de TV paga e ainda está disponível em tempo real pela internet, mídias sociais e aplicativo para smartphone (IOS e Androide). Em 2015 passou a transmitir sua programação em sinal digital.

Para tal estudo, foi escolhido o método estudo de caso. A análise aprofundada da TV Diário justifica a escolha do estudo de caso como método científico. Segundo Yin (2005), o estudo de caso permite uma análise dos fenômenos contemporâneos dentro do seu contexto real.

A amostra foi escolhida a partir dos seguintes dados: clientes que anunciam e que não anunciam na TV Diário. A seguir a quantidade de clientes anunciantes e não do mês de março 2018:

a) os clientes anunciantes da TV Diário.

Total de clientes da TV Diário em março de 2018 foram 82 (TV DIÁRIO, 2018).

b) os clientes não anunciantes foram selecionados por intermédio do programa SMART, (ferramenta que mapeia anunciantes de todas as emissoras de TV e rádio), totalizando em março de 2018, 100 (TV DIÁRIO, 2018).

Foi enviado questionário para todos os clientes acima.

Após a elaboração do questionário, foi realizado um pré-teste com 05 especialistas em TV Aberta e com 05 clientes (anunciantes e não anunciantes) para validar o questionário. Vergara (2012) cita que o pesquisador deve submeter a “juízes”, pessoas que tenham expertise no tema e em metodologia da pesquisa e em alguns casos, que sejam pessoas do mercado ou do setor público.

$\mathrm{O}$ instrumento para coleta de dados qualitativos foi feito por meio de entrevistas em profundidade com 01 gestor comercial da TV Diário e 05 anunciantes. A entrevista em profundidade segundo Duarte e Barros (2011), são entrevistas individuais, uma técnica qualitativa que explora um assunto a partir da busca por informações, percepções e experiências de informantes para analisá-las e apresentá-las de maneira estruturadas. Um roteiro foi elaborado para essa fase.

Após a análise em SPSS 20, os dados quantitativos consolidados foram exportados de volta ao EXCEL em forma de Tabelas que se mostraram mais explicativas do que os gráficos gerados.

A seguir Tabelas e Gráficos de dados comparativos, mas relevantes, entre clientes anunciantes e não anunciantes da TV Diário. 
Tabela 2 - Através de que canal sua empresa compra sua mídia?

\begin{tabular}{l|c|r|r|r}
\hline \multicolumn{1}{c|}{ Canal de Mídia } & \multicolumn{2}{|c|}{ Anunciante } & \multicolumn{2}{c}{ Não anunciante } \\
\cline { 2 - 5 } & $\mathbf{N}$ & \multicolumn{1}{c|}{$\%$} & N & \multicolumn{1}{c}{$\%$} \\
\hline Direto na emissora & 7 & 36,84 & 2 & 20,00 \\
\hline $\begin{array}{l}\text { Por uma agência de } \\
\text { propaganda }\end{array}$ & 7 & 36,84 & 8 & 80,00 \\
\hline $\begin{array}{l}\text { Por um agenciador } \\
\text { autônomo }\end{array}$ & 5 & 26,32 & 0 & 0,00 \\
\hline Total & $\mathbf{1 9}$ & $\mathbf{1 0 0}$ & $\mathbf{1 0}$ & $\mathbf{1 0 0}$ \\
\hline
\end{tabular}

Fonte: Elaborada pela autora (2018).

Os clientes anunciantes compram direto na emissora ou por agenciadores autônomos e os não anunciantes concentram suas compras por agências.

Tabela 3 - $\mathrm{O}$ atendimento da TV Diário foi relevante para sua compra de mídia?

\begin{tabular}{l|c|r|c|r}
\hline \multirow{2}{*}{ Relevância } & \multicolumn{2}{c|}{ Anunciante } & \multicolumn{2}{c}{ Não anunciante } \\
\cline { 2 - 5 } & $\mathbf{N}$ & $\mathbf{\%}$ & N & \multicolumn{1}{c}{ \% } \\
\hline Muito improvável & 0 & 0,00 & 1 & 10,00 \\
\hline Indiferente & 2 & 10,53 & 2 & 20,00 \\
\hline Provável & 6 & 31,58 & 4 & 40,00 \\
\hline Muito provável & 11 & 57,89 & 3 & 30,00 \\
\hline Total & $\mathbf{1 9}$ & $\mathbf{1 0 0}$ & $\mathbf{1 0}$ & $\mathbf{1 0 0}$ \\
\hline
\end{tabular}

Fonte: Elaborada pela autora (2018).

Tabela 4 - Qual dos atributos abaixo listados representam o seu atendimento comercial da TV Diário?

\begin{tabular}{|c|c|c|c|c|c|c|c|}
\hline \multirow[t]{2}{*}{ Atributos } & \multirow[t]{2}{*}{ Relevância } & \multicolumn{2}{|c|}{ Anunciante } & \multicolumn{2}{|c|}{ Não anunciante } & \multirow[t]{2}{*}{ Total } & \multirow[t]{2}{*}{$\%$} \\
\hline & & $\mathbf{N}$ & $\%$ & $\mathbf{N}$ & $\%$ & & \\
\hline \multirow{3}{*}{ Conhecimento sobre a emissora } & Indiferente & 1 & 5,88 & 0 & 0,00 & 1 & 3,85 \\
\hline & Provável & 9 & 52,94 & 1 & 11,11 & 10 & 38,46 \\
\hline & Muito provável & 7 & 41,18 & 8 & 88,89 & 15 & 57,69 \\
\hline \multicolumn{2}{|l|}{ Total } & 17 & 100 & 9 & 100 & 26 & 100 \\
\hline \multirow{3}{*}{ Empatia } & Indiferente & 2 & 12,50 & 0 & 0,00 & 2 & 8,00 \\
\hline & Provável & 8 & 50,00 & 3 & 33,33 & 11 & 44,00 \\
\hline & Muito provável & 6 & 37,50 & 6 & 66,67 & 12 & 48,00 \\
\hline \multicolumn{2}{|l|}{ Total } & 16 & 100 & 9 & 100 & 25 & 100 \\
\hline \multirow{3}{*}{ Disponibilidade } & Indiferente & 1 & 6,25 & 1 & 11,11 & 2 & 8,00 \\
\hline & Provável & 11 & 68,75 & 2 & 22,22 & 13 & 52,00 \\
\hline & Muito provável & 4 & 25,00 & 6 & 66,67 & 10 & 40,00 \\
\hline \multicolumn{2}{|l|}{ Total } & 16 & 100 & 9 & 100 & 25 & 100 \\
\hline \multirow{5}{*}{ Persistência } & Muito improvável & 1 & 7,14 & 0 & 0,00 & 1 & 4,55 \\
\hline & Improvável & 1 & 7,14 & 1 & 12,50 & 2 & 9,09 \\
\hline & Indiferente & 1 & 7,14 & 3 & 37,50 & 4 & 18,18 \\
\hline & Provável & 7 & 50,00 & 2 & 25,00 & 9 & 40,91 \\
\hline & Muito provável & 6 & 42,86 & 3 & 37,50 & 9 & 40,91 \\
\hline \multicolumn{2}{|l|}{ Total } & 14 & 100 & 8 & 100 & 22 & 100 \\
\hline \multirow{2}{*}{ Negociação } & Provável & 9 & 50,00 & 2 & 20,00 & 11 & 39,29 \\
\hline & Muito provável & 9 & 50,00 & 8 & 80,00 & 17 & 60,71 \\
\hline \multicolumn{2}{|l|}{ Total } & 18 & 100 & 10 & 100 & 28 & 100 \\
\hline
\end{tabular}

Fonte: Elaborada pela autora (2018).

Em relação a Tabela 04 ao ser realizada uma análise de fatores para os atributos, tem-se: 
Para empresas anunciantes os atributos que respondem por 58\% em grau de importância ao atendimento comercial são: Conhecimento sobre a emissora, Empatia, Disponibilidade e Negociação; Persistência responde por apenas $20 \%$.

Para empresas não anunciantes os atributos que respondem por $51 \%$ em grau de importância ao atendimento comercial são: Conhecimento da emissora, Empatia e Disponibilidade; Persistência responde por $31 \%$.

Para ambas empresas anunciante e não anunciantes os atributos que respondem em grau de importância ao atendimento comercial são: Conhecimento da emissora, Empatia e Disponibilidade $(55,78 \%)$.

Tabela 05 - Os formatos diferenciados da TV Diário foram decisivos para a compra de mídia da minha empresa

\begin{tabular}{l|c|r|c|r}
\hline \multirow{2}{*}{ Nível } & \multicolumn{2}{|c|}{ Anunciante } & \multicolumn{2}{c}{ Não anunciante } \\
\cline { 2 - 5 } & $\mathbf{N}$ & \% & N & \multicolumn{1}{c}{$\%$} \\
\hline Muito improvável & 1 & 5,26 & 0 & 0,00 \\
\hline Improvável & 0 & 0,00 & 1 & 10,00 \\
\hline Indiferente & 2 & 10,53 & 2 & 20,00 \\
\hline Provável & 7 & 36,84 & 5 & 50,00 \\
\hline Muito provável & 9 & 47,37 & 2 & 20,00 \\
\hline Total & $\mathbf{1 9}$ & $\mathbf{1 0 0}$ & $\mathbf{1 0}$ & $\mathbf{1 0 0}$ \\
\hline
\end{tabular}

Fonte: Elaborada pela autora (2018).

Existe uma atenção aos formatos diferenciados e esse é um fator relevante.

Tabela 06 - Diante da afirmação "As pessoas não assistem mais TV por causa da internet"

\begin{tabular}{l|c|r|c|r}
\hline \multirow{2}{*}{ Nível } & \multicolumn{2}{c|}{ Anunciante } & \multicolumn{2}{c}{ Não anunciante } \\
\cline { 2 - 5 } & $\mathbf{N}$ & \multicolumn{1}{c|}{$\%$} & $\mathbf{N}$ & \multicolumn{1}{c}{$\%$} \\
\hline Discordo totalmente & 5 & 26,32 & 5 & 50,00 \\
\hline Discordo parcialmente & 8 & 42,11 & 4 & 40,00 \\
\hline Indiferente & 1 & 5,26 & 0 & 0,00 \\
\hline Concordo parcialmente & 3 & 15,79 & 1 & 10,00 \\
\hline Concordo totalmente & 2 & 10,53 & 0 & 0,00 \\
\hline Total & $\mathbf{1 9}$ & $\mathbf{1 0 0}$ & $\mathbf{1 0}$ & $\mathbf{1 0 0}$ \\
\hline
\end{tabular}

Fonte: Elaborada pela autora (2018).

Tabela 07 - Assinale abaixo as plataformas digitais que sua empresa utiliza. (pode ser mais de 01 opção)

\begin{tabular}{l|c|r|c|r|r|r}
\hline \multirow{2}{*}{ Nível } & \multicolumn{2}{c|}{ Anunciante } & \multicolumn{2}{c|}{ Não anunciante } & \multicolumn{2}{c}{ Não Resposta } \\
\cline { 2 - 7 } & $\mathbf{N}$ & \multicolumn{1}{c}{$\%$} & $\mathbf{N}$ & \% & N & \% \\
\hline Site & 17 & 37,78 & 8 & 17,78 & 20 & 44,44 \\
\hline Instagram & 15 & 33,33 & 10 & 22,22 & 20 & 44,44 \\
\hline Facebook & 17 & 37,78 & 9 & 20,00 & 19 & 42,22 \\
\hline Twitter & 4 & 8,89 & 1 & 2,22 & 40 & 88,89 \\
\hline E-commerce & 4 & 8,89 & 1 & 2,22 & 40 & 88,89 \\
\hline Outro & 3 & 6,67 & 1 & 2,22 & 41 & 91,11 \\
\hline
\end{tabular}

Fonte: Elaborada pela autora (2018). 
Os anunciantes ou não, acreditam que os consumidores assistem TV e eles usam plataformas digitais para divulgar seus produtos.

Tabela 08 - Para comprar sua mídia de TV você utiliza qual ou quais dos critérios abaixo?

\begin{tabular}{|c|c|c|c|c|c|c|c|}
\hline \multirow[t]{2}{*}{ Critérios } & \multirow[t]{2}{*}{ Usabilidade } & \multicolumn{2}{|c|}{ Anunciante } & \multicolumn{2}{|c|}{ Não anunciante } & \multirow[t]{2}{*}{ Total } & \multirow[t]{2}{*}{$\%$} \\
\hline & & $\mathbf{N}$ & $\%$ & $\mathbf{N}$ & $\%$ & & \\
\hline \multirow{5}{*}{$\begin{array}{l}\text { GRP - Gross Rating Point, ferramenta que mede } \\
\text { a intensidade de mídia }\end{array}$} & Não uso & 0 & 0,00 & 8 & 50,00 & 8 & 32,00 \\
\hline & Pouco uso & 1 & 11,11 & 0 & 0,00 & 1 & 4,00 \\
\hline & Indiferente & 0 & 0,00 & 1 & 6,25 & 1 & 4,00 \\
\hline & uso & 7 & 77,78 & 4 & 25,00 & 11 & 44,00 \\
\hline & $\begin{array}{l}\text { Uso } \\
\text { bastante }\end{array}$ & 1 & 11,11 & 3 & 18,75 & 4 & 16,00 \\
\hline \multicolumn{2}{|l|}{ Total } & 9 & 100 & 16 & 100 & 25 & 100 \\
\hline \multirow{4}{*}{$\begin{array}{l}\text { CPM - Custo por Mil ferramenta que calcula } \\
\text { quanto pago por cada mil telespectadores } \\
\text { atingidos }\end{array}$} & Não uso & 0 & 0,00 & 7 & 43,75 & 7 & 28,00 \\
\hline & Indiferente & 0 & 0,00 & 1 & 6,25 & 1 & 4,00 \\
\hline & uso & 3 & 33,33 & 5 & 31,25 & 8 & 32,00 \\
\hline & $\begin{array}{l}\text { Uso } \\
\text { bastante }\end{array}$ & 6 & 66,67 & 3 & 18,75 & 9 & 36,00 \\
\hline \multicolumn{2}{|l|}{ Total } & 9 & 100 & 16 & 100 & 25 & 100 \\
\hline \multirow{5}{*}{ Análise de audiência } & Não uso & 0 & 0,00 & 1 & 5,88 & 1 & 3,85 \\
\hline & Pouco uso & 0 & 0,00 & 1 & 5,88 & 1 & 3,85 \\
\hline & Indiferente & 0 & 0,00 & 2 & 11,76 & 2 & 7,69 \\
\hline & uso & 5 & 55,56 & 8 & 47,06 & 13 & 50,00 \\
\hline & $\begin{array}{l}\text { Uso } \\
\text { bastante }\end{array}$ & 4 & 44,44 & 5 & 29,41 & 9 & 34,62 \\
\hline \multicolumn{2}{|l|}{ Total } & 9 & 100 & 17 & 100 & 26 & 100 \\
\hline \multirow{4}{*}{$\begin{array}{l}\text { Retorno sobre o investimento - o quanto tenho } \\
\text { resultado com a mídia }\end{array}$} & Pouco uso & 3 & 37,50 & 2 & 10,53 & 5 & 18,52 \\
\hline & Indiferente & 1 & 12,50 & 2 & 10,53 & 3 & 11,11 \\
\hline & uso & 1 & 12,50 & 7 & 36,84 & 8 & 29,63 \\
\hline & $\begin{array}{l}\text { Uso } \\
\text { bastante }\end{array}$ & 3 & 37,50 & 8 & 42,11 & 11 & 40,74 \\
\hline \multicolumn{2}{|l|}{ Total } & 8 & 100 & 19 & 100 & 27 & 100 \\
\hline \multirow{4}{*}{ Credibilidade do apresentador } & Pouco uso & 0 & 0,00 & 1 & 5,88 & 1 & 3,85 \\
\hline & Indiferente & 0 & 0,00 & 3 & 17,65 & 3 & 11,54 \\
\hline & uso & 5 & 55,56 & 9 & 52,94 & 14 & 53,85 \\
\hline & $\begin{array}{l}\text { Uso } \\
\text { bastante }\end{array}$ & 4 & 44,44 & 4 & 23,53 & 8 & 30,77 \\
\hline \multicolumn{2}{|l|}{ Total } & 9 & 100 & 17 & 100 & 26 & 100 \\
\hline \multirow{3}{*}{ Verba disponível } & Pouco uso & 0 & 0,00 & 2 & 11,76 & 2 & 7,69 \\
\hline & uso & 4 & 44,44 & 5 & 29,41 & 9 & 34,62 \\
\hline & $\begin{array}{l}\text { Uso } \\
\text { bastante }\end{array}$ & 5 & 55,56 & 10 & 58,82 & 15 & 57,69 \\
\hline \multicolumn{2}{|l|}{ Total } & 9 & 100 & 17 & 100 & 26 & 100 \\
\hline
\end{tabular}

Fonte: Elaborada pela autora (2018).

Em relação aos critérios utilizados para a compra da mídia TV, tem-se:

Para ambas empresas anunciante e não anunciantes os atributos que respondem por 69,71\% em grau de usabilidade ou não dos critérios apresentados, tem-se: GRP, CPM, Análise de audiência, e Verba disponível com 46,18\%; Retorno sobre investimento 23,53\%.

A Seguir resultados dos dados das perguntas para clientes anunciantes. 
Tabela 09 - Há quanto tempo sua empresa anuncia na TV Diário?

\begin{tabular}{l|c|r}
\hline \multicolumn{1}{c|}{ Tempo } & N & \multicolumn{2}{c}{ \% } \\
\hline Menos de 6 meses & 1 & 5,3 \\
\hline 6 meses a 1 ano & 3 & 15,8 \\
\hline 1 a 2 anos & 3 & 15,8 \\
\hline 3 anos ou mais & 12 & 63,2 \\
\hline Total & $\mathbf{1 9}$ & $\mathbf{1 0 0 , 0}$ \\
\hline
\end{tabular}

Fonte: Elaborada pela autora (2018).

É possível ver a fidelidade dos anunciantes da TV Diário, com maior percentual de clientes com 3 anos ou mais anunciando.

Tabela 10 -_O fato da TV Diário ser uma TV com conteúdo regional, teve relevância na sua decisão de compra de mídia?

\begin{tabular}{l|c|r}
\hline \multicolumn{1}{c|}{ Relevância } & N & \multicolumn{2}{c}{ \% } \\
\hline Muito improvável & 10 & 52,6 \\
\hline Indiferente & 1 & 5,3 \\
\hline Provável & 7 & 36,8 \\
\hline Não reposta & 1 & 5,3 \\
\hline Total & $\mathbf{1 9}$ & $\mathbf{1 0 0 , 0}$ \\
\hline
\end{tabular}

Fonte: Elaborada pela autora (2018).

O conteúdo regional é bem recebido, porém não é decisivo.

Tabela 11 - Como sua empresa conheceu a TV Diário?

\begin{tabular}{|c|c|c|c|}
\hline Meio & Relevância & $\mathbf{N}$ & $\%$ \\
\hline \multirow{6}{*}{$\begin{array}{l}\text { Através de visita de atendimento } \\
\text { comercial da emissora }\end{array}$} & Muito Improvável & 2 & 10,5 \\
\hline & Improvável & 1 & 5,3 \\
\hline & Indiferente & 1 & 5,3 \\
\hline & Provável & 5 & 26,3 \\
\hline & Muito provável & 5 & 26,3 \\
\hline & Não resposta & 5 & 26,3 \\
\hline \multicolumn{2}{|l|}{ Total } & 19 & $\begin{array}{r}100, \\
0\end{array}$ \\
\hline \multirow{5}{*}{ Sou telespectador da TV Diário } & Improvável & 3 & 15,8 \\
\hline & Indiferente & 3 & 15,8 \\
\hline & Provável & 7 & 36,8 \\
\hline & Muito provável & 4 & 21,1 \\
\hline & Não resposta & 2 & 10,5 \\
\hline \multicolumn{2}{|l|}{ Total } & 19 & $\begin{array}{r}100, \\
0\end{array}$ \\
\hline \multirow{6}{*}{$\begin{array}{l}\text { Indicação de uma agência ou } \\
\text { agenciador autônomo }\end{array}$} & Muito Improvável & 3 & 15,8 \\
\hline & Improvável & 1 & 5,3 \\
\hline & Indiferente & 2 & 10,5 \\
\hline & Provável & 5 & 26,3 \\
\hline & Muito provável & 6 & 31,6 \\
\hline & Não resposta & 2 & 10,5 \\
\hline \multicolumn{2}{|l|}{ Total } & 19 & $\begin{array}{r}100, \\
0\end{array}$ \\
\hline \multirow{4}{*}{$\begin{array}{l}\text { Sugestão de outra empresa } \\
\text { anunciante }\end{array}$} & Muito Improvável & 4 & 21,1 \\
\hline & Improvável & 3 & 15,8 \\
\hline & Indiferente & 3 & 15,8 \\
\hline & Provável & 2 & 10,5 \\
\hline
\end{tabular}


Tabela 11 - Como sua empresa conheceu a TV Diário?

\begin{tabular}{|c|c|c|c|}
\hline Meio & Relevância & $\mathbf{N}$ & $\%$ \\
\hline & Muito provável & 2 & 10,5 \\
\hline & Não resposta & 5 & 26,3 \\
\hline Total & & 19 & $\begin{array}{c}100 \\
0\end{array}$ \\
\hline
\end{tabular}

Fonte: Elaborada pela autora (2018).

Para empresas anunciantes a forma como elas tiveram conhecimento sobre a Tv Diário foi por intermédio de visita de agenciador de propaganda da emissora, por uma agência ou agenciador autônomos e por serem telespectadores da emissora.

A seguir resultados exclusivos de clientes não anunciantes, que estão subdivididos em que já anunciaram e que nunca anunciaram. Começaremos com os que já anunciaram.

Tabela 12 - Sua empresa já anunciou na TV Diário?

\begin{tabular}{l|r|r}
\multicolumn{1}{c|}{ Resposta } & N & \multicolumn{2}{c}{ \% } \\
\hline Sim & 12 & 46,2 \\
\hline Não & 14 & 53,8 \\
\hline Total & $\mathbf{2 6}$ & $\mathbf{1 0 0 , 0}$ \\
\hline
\end{tabular}

Fonte: Elaborada pela autora (2018).

É interessante observar o potencial de possíveis clientes para conhecer e anunciar na TV Diário.

Tabela 132 - Como conheceu a TV Diário?

\begin{tabular}{|c|c|c|c|}
\hline Meio & Relevância & $\mathbf{N}$ & $\%$ \\
\hline \multirow{5}{*}{$\begin{array}{l}\text { Indicação de } \\
\text { uma outra } \\
\text { empresa }\end{array}$} & $\begin{array}{l}\text { Muito } \\
\text { improvável }\end{array}$ & 4 & 15,4 \\
\hline & Improvável & 1 & 3,8 \\
\hline & Indiferente & 3 & 11,5 \\
\hline & Provável & 1 & 3,8 \\
\hline & System & 17 & 65,4 \\
\hline \multicolumn{2}{|l|}{ Total } & 26 & 100,0 \\
\hline \multirow{6}{*}{$\begin{array}{l}\text { Sou } \\
\text { telespectador } \\
\text { da emissora }\end{array}$} & $\begin{array}{l}\text { Muito } \\
\text { improvável }\end{array}$ & 2 & 7,7 \\
\hline & Improvável & 1 & 3,8 \\
\hline & Indiferente & 1 & 3,8 \\
\hline & Provável & 3 & 11,5 \\
\hline & $\begin{array}{l}\text { Muito } \\
\text { provável }\end{array}$ & 3 & 11,5 \\
\hline & Não resposta & 16 & 61,5 \\
\hline \multicolumn{2}{|l|}{ Total } & 26 & 100,0 \\
\hline \multirow{4}{*}{$\begin{array}{l}\text { Indicação de } \\
\text { uma agência } \\
\text { de } \\
\text { propaganda }\end{array}$} & $\begin{array}{l}\text { Muito } \\
\text { improvável }\end{array}$ & 1 & 3,8 \\
\hline & Improvável & 2 & 7,7 \\
\hline & $\begin{array}{l}\text { Muito } \\
\text { provável }\end{array}$ & 6 & 23,1 \\
\hline & Não resposta & 17 & 65,4 \\
\hline \multicolumn{2}{|l|}{ Total } & 26 & 100,0 \\
\hline
\end{tabular}




\begin{tabular}{l|l|r|r}
\multirow{4}{*}{$\begin{array}{l}\text { Visita de um } \\
\text { atendimento }\end{array}$} & $\begin{array}{l}\text { Muito } \\
\text { improvável }\end{array}$ & 2 & 7,7 \\
\cline { 2 - 4 } comercial & Indiferente & 1 & 3,8 \\
\cline { 2 - 4 } & Provável & 1 & 3,8 \\
\cline { 2 - 4 } & $\begin{array}{l}\text { Muito } \\
\text { provável }\end{array}$ & 5 & 19,2 \\
\cline { 2 - 4 } & Não resposta & 17 & 65,4 \\
\hline \multicolumn{1}{|c|}{ Total } & $\mathbf{2 6}$ & $\mathbf{1 0 0 , 0}$ \\
\hline
\end{tabular}

Fonte: Elaborada pela autora (2018).

Nesse item é possível perceber a influência da agência de propaganda e a diminuição da relevância do agenciador de propaganda do veículo.

Tabela 143 - Qual fator ou fatores fizeram sua empresa deixar de anunciar na TV Diário?

\begin{tabular}{|c|c|c|c|}
\hline Fatores & Relevância & $\mathbf{N}$ & $\%$ \\
\hline \multirow{5}{*}{ Negociação } & Muito improvável & 3 & 11,5 \\
\hline & Improvável & 2 & 7,7 \\
\hline & Indiferente & 3 & 11,5 \\
\hline & Muito provável & 1 & 3,8 \\
\hline & Não resposta & 17 & 65,4 \\
\hline \multicolumn{2}{|c|}{ Total } & 26 & 100 \\
\hline \multirow{6}{*}{ Retorno sobre investimento } & Muito improvável & 1 & 3,8 \\
\hline & Improvável & 1 & 3,8 \\
\hline & Indiferente & 3 & 11,5 \\
\hline & Provável & 1 & 3,8 \\
\hline & Muito provável & 3 & 11,5 \\
\hline & Não resposta & 17 & 65,4 \\
\hline \multicolumn{2}{|c|}{ Total } & 26 & 100 \\
\hline \multirow{5}{*}{$\begin{array}{l}\text { Posicionamento da sua } \\
\text { marca }\end{array}$} & Improvável & 2 & 7,7 \\
\hline & Indiferente & 3 & 11,5 \\
\hline & Provável & 2 & 7,7 \\
\hline & Muito provável & 3 & 11,5 \\
\hline & Não resposta & 16 & 61,5 \\
\hline \multicolumn{2}{|c|}{ Total } & 26 & 100 \\
\hline \multirow{5}{*}{$\begin{array}{l}\text { Falta de atendimento } \\
\text { adequado }\end{array}$} & Muito improvável & 5 & 19,2 \\
\hline & Improvável & 1 & 3,8 \\
\hline & Indiferente & 2 & 7,7 \\
\hline & Provável & 1 & 3,8 \\
\hline & Não resposta & 17 & 65,4 \\
\hline \multicolumn{2}{|c|}{ Total } & 26 & 100 \\
\hline \multirow{6}{*}{ Qualidade da programação } & Muito improvável & 1 & 3,8 \\
\hline & Improvável & 4 & 15,4 \\
\hline & Indiferente & 1 & 3,8 \\
\hline & Provável & 1 & 3,8 \\
\hline & Muito provável & 2 & 7,7 \\
\hline & Não resposta & 17 & 65,4 \\
\hline \multicolumn{2}{|c|}{ Total } & 26 & 100,0 \\
\hline \multirow{4}{*}{$\begin{array}{l}\text { Diminuição da Verba por } \\
\text { causa da crise financeira }\end{array}$} & Muito improvável & 1 & 3,8 \\
\hline & Provável & 5 & 19,2 \\
\hline & Muito provável & 3 & 11,5 \\
\hline & Não resposta & 17 & 65,4 \\
\hline \multicolumn{2}{|c|}{ Total } & 26 & 100,0 \\
\hline
\end{tabular}

Fonte: Elaborada pela autora (2018). 
Com relação a esse ponto é notória a importância do retorno sobre o investimento e o posicionamento da marca do cliente com relação a TV Diário. A diminuição da verba por conta da crise financeira também é sugestiva.

\begin{tabular}{l|c|r}
\multicolumn{1}{c}{ Tabela 15- Sua empresa anunciaria novamente na TV Diário? } \\
\hline \multicolumn{1}{c|}{ Resposta } & $\mathbf{N}$ & \% \\
\hline Sim & 8 & 30,8 \\
\hline Não & 2 & 7,7 \\
\hline Não resposta & 16 & 61,5 \\
\hline Total & $\mathbf{2 6}$ & $\mathbf{1 0 0}$ \\
\hline
\end{tabular}

Fonte: Elaborada pela autora (2018).

É importante perceber que existe um potencial de retorno de anunciantes para a Tv Diário.

As próximas Tabelas serão de clientes que nunca anunciaram.

Tabela 16 - Sua empresa já recebeu uma visita de um atendimento comercial da TV Diário?

\begin{tabular}{l|c|r}
\hline \multicolumn{1}{c|}{ Resposta } & N & \multicolumn{2}{c}{ \% } \\
\hline Sim & 10 & 38,46 \\
\hline Não & 3 & 11,53 \\
\hline Não resposta & 13 & 50,00 \\
\hline Total & $\mathbf{2 6}$ & $\mathbf{1 0 0}$ \\
\hline
\end{tabular}

Fonte: Elaborada pela autora (2018).

Esse item percebe-se que houve visitas a clientes que nunca anunciaram e como temos 13 que não responderam esse resultado pode trazer dúvidas.

\begin{tabular}{l|c|r}
\multicolumn{2}{c}{ Tabela 16- Através de que canal sua empresa compra sua mídia? } \\
\hline \multicolumn{1}{c}{ Canal de Mídia } & $\mathbf{N}$ & \multicolumn{1}{c}{ Não anunciante } \\
\cline { 2 - 3 } & 2 & 16,67 \\
\hline Direto na emissora & 11 & 91,66 \\
\hline Por uma agência de propaganda & $\mathbf{1 2}$ & $\mathbf{1 0 0}$ \\
\hline Total
\end{tabular}

Fonte: Elaborada pela autora (2018).

Novamente percebemos a importância das agências no processo de compra de mídia.

Tabela 17 - Sua empresa conhece os formatos diferenciados da TV Diário?

\begin{tabular}{l|c|r}
\hline \multicolumn{1}{c|}{ Resposta } & N & \multicolumn{2}{c}{$\%$} \\
\hline Sim & 7 & 26,92 \\
\hline Não & 5 & 19,23 \\
\hline Não resposta & 14 & 53,84 \\
\hline Total & $\mathbf{2 6}$ & $\mathbf{1 0 0}$ \\
\hline
\end{tabular}

Fonte: Elaborada pela autora (2018). 
Percebemos que uma boa quantidade conhece e que deve haver a possibilidade de mostrar esses formatos aos anunciantes.

Tabela 18 - O fato da TV Diário se uma TV com conteúdo regional pode ter relevância na sua decisão de compra da mídia?

\begin{tabular}{l|c|r}
\hline \multirow{2}{*}{ Relevância } & \multicolumn{2}{c}{ Não Anunciante } \\
\cline { 2 - 3 } & $\mathbf{N}$ & \% \\
\hline Muito improvável & 1 & 7,69 \\
\hline Improvável & 1 & 7,69 \\
\hline Indiferente & 2 & 15,38 \\
\hline Provável & 7 & 53,85 \\
\hline Muito provável & 2 & 15,38 \\
\hline Total & $\mathbf{1 3}$ & $\mathbf{1 0 0}$ \\
\hline
\end{tabular}

Fonte: Elaborada pela autora (2018).

O regionalismo é tratado de forma positiva pelos que nunca anunciaram.

Tabela 19- Assinale abaixo as plataformas digitais que sua empresa utiliza (pode ser mais de 01 opção)

\begin{tabular}{l|c|r}
\hline \multirow{2}{*}{ Meio } & \multicolumn{2}{c}{ Não anunciante } \\
\cline { 2 - 3 } & N & \multicolumn{1}{c}{$\%$} \\
\hline Site & 11 & 42,30 \\
\hline Instagram & 12 & 46,15 \\
\hline Facebook & 11 & 42,30 \\
\hline Twitter & 2 & 7,69 \\
\hline E-commerce & 4 & 15,38 \\
\hline Outro & 3 & 11,53 \\
\hline Font
\end{tabular}

Fonte: Elaborada pela autora (2018).

Tabela 204 - Diante da Afirmação “As pessoas não assistem mais TV por causa da Internet”

\begin{tabular}{l|c|r}
\hline \multirow{2}{*}{ Concordância } & \multicolumn{2}{c}{ Não Anunciante } \\
\cline { 2 - 3 } & $\mathbf{N}$ & \% \\
\hline Discordo Totalmente & 1 & 53,69 \\
\hline Discordo parcialmente & 7 & 23,08 \\
\hline Indiferente & 3 & 15,38 \\
\hline Concordo parcialmente & 2 & $\mathbf{1 0 0}$ \\
\hline Total & $\mathbf{1 2}$ & \multicolumn{2}{c}{} \\
\hline
\end{tabular}

Fonte: Elaborada pela autora (2018).

A TV aberta e a internet existem de forma harmônica, essa é percepção de quase todos os que nunca anunciaram na TV Diário.

Tabela 21 - Para comprar sua mídia de TV você utiliza qual ou quais dos critérios abaixo?

\begin{tabular}{l|l|r|r}
\hline \multirow{2}{*}{ Critérios } & Usabilidade & \multicolumn{2}{|c}{ Anunciante } \\
\cline { 3 - 4 } & & $\mathbf{N}$ & \multicolumn{1}{c}{$\%$} \\
\hline \multirow{3}{*}{$\begin{array}{l}\text { GRP - Gross Rating Point, ferramenta } \\
\text { que mede a intensidade de mídia }\end{array}$} & Não uso & 2 & 15,38 \\
\cline { 2 - 4 } & Pouco uso & 1 & 7,69 \\
\cline { 2 - 4 } & uso & 7 & 53,85 \\
\cline { 2 - 4 } & Uso muito & 3 & 23,08
\end{tabular}


Tabela 21 - Para comprar sua mídia de TV você utiliza qual ou quais dos critérios abaixo?

\begin{tabular}{|c|c|c|c|}
\hline Critérios & Usabilidade & \multicolumn{2}{|c|}{ Anunciante } \\
\hline \multicolumn{2}{|l|}{ Total } & 13 & 100 \\
\hline \multirow{4}{*}{$\begin{array}{l}\text { CPM - Custo por Mil ferramenta que } \\
\text { calcula quanto pago por cada mil } \\
\text { telespectadores atingidos }\end{array}$} & Não uso & 1 & 8,33 \\
\hline & Pouco uso & 1 & 8,33 \\
\hline & uso & 7 & 58,33 \\
\hline & Uso muito & 3 & 25,00 \\
\hline \multicolumn{2}{|l|}{ Total } & 12 & 100 \\
\hline \multirow{3}{*}{ Análise de audiência } & Não uso & 1 & 7,69 \\
\hline & uso & 6 & 46,15 \\
\hline & Uso muito & 6 & 46,15 \\
\hline \multicolumn{2}{|l|}{ Total } & 13 & 100 \\
\hline \multirow{3}{*}{$\begin{array}{l}\text { Retorno sobre o investimento - o } \\
\text { quanto tenho resultado com a mídia }\end{array}$} & Indiferente & 1 & 8,33 \\
\hline & uso & 7 & 58,33 \\
\hline & Uso muito & 4 & 33,33 \\
\hline \multicolumn{2}{|l|}{ Total } & 12 & 100 \\
\hline \multirow{5}{*}{ Credibilidade do apresentador } & Não uso & 1 & 7,69 \\
\hline & Pouco uso & 1 & 7,69 \\
\hline & Indiferente & 2 & 15,38 \\
\hline & uso & 6 & 46,15 \\
\hline & Uso muito & 3 & 23,08 \\
\hline \multicolumn{2}{|l|}{ Total } & 13 & 100 \\
\hline \multirow{3}{*}{ Verba disponível } & Não uso & 1 & 7,69 \\
\hline & uso & 3 & 23,08 \\
\hline & Uso muito & 9 & 69,23 \\
\hline \multicolumn{2}{|l|}{ Total } & 13 & 100 \\
\hline \multirow{3}{*}{ Outros } & Não uso & 1 & 7,69 \\
\hline & uso & 6 & 46,15 \\
\hline & Uso muito & 6 & 46,15 \\
\hline
\end{tabular}

Fonte: Elaborada pela autora (2018).

Como nos clientes anunciantes e nos que já anunciaram na TV Diário o uso de ferramentas técnicas de mídia são utilizadas de maneira predominante.

$\mathrm{Na}$ análise qualitativa, após a leitura das entrevistas do estudo, codificamos trechos da entrevista transcrita, para que possamos a apresentar em forma de tabela.

Criamos 04 grandes temas, que são as categorias, conforme a lista a seguir: fatores técnicos para escolha, percepção sobre a TV Diário, contexto digital, contexto político econômico.

Segue Tabela 22 construída a partir das análises das entrevistas com clientes anunciantes e não anunciantes. 


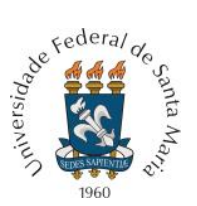

PROGRAMA DE PÓS-GRADUAÇÃO EM COMUNICAÇÃO DA UNIVERSIDADE FEDERAL DE SANTA MARIA

Tabela 22 - Análise de conteúdo

FATORES QUE INTERFEREM NA COMPRA DE ESPAÇOS PUBLICITÁRIOS EM TV ABERTA

\begin{tabular}{|c|c|c|c|}
\hline CATEGORIA & SUBCATEGORIA & UNIDADE DE REGISTRO & UNIDADE DE CONTEXTO \\
\hline \multirow{12}{*}{$\begin{array}{l}\text { 1.FATORES PARA } \\
\text { A ESCOLHA DOS } \\
\text { MEIOS }\end{array}$} & \multirow{7}{*}{ Uso de técnicas para comprar mídia } & CPM & $\begin{array}{c}\text { " Sempre usamos análise de C P M." } \\
\text { Entrevistado } 3\end{array}$ \\
\hline & & \multirow{4}{*}{ Retorno sobre o investimento } & $\begin{array}{c}\text { "Fazemos pesquisa através da captação de alunos } \\
\text { para medir o retorno". Entrevistado } 1\end{array}$ \\
\hline & & & $\begin{array}{c}\text { " Através do tipo de brinde, que para cada } \\
\text { emissora é diferente, medimos o resultado do } \\
\text { veículo." Entrevistado } 2 \\
\end{array}$ \\
\hline & & & $\begin{array}{c}\text { " A TV Aberta é a principal mídia, sempre nos dá } \\
\text { o melhor resultado, não ficamos sem ela." } \\
\text { Entrevistado } 3\end{array}$ \\
\hline & & & $\begin{array}{c}\text { "Fala com muita gente de forma rápida e traz } \\
\text { mais visibibilidade" Entrevistado } 1\end{array}$ \\
\hline & & Análise de audiência & $\begin{array}{c}\text { "Uso várias pesquisas para acompanhar a } \\
\text { audiência da TV Aberta, como a PBM." } \\
\text { Entrevistado } 3 \\
\end{array}$ \\
\hline & & & $\begin{array}{l}\text { No nordeste a TV Aberta é muito forte, não tem } \\
\text { como fazer varejo sem ela." Entrevistado } 3\end{array}$ \\
\hline & \multirow{2}{*}{ A influência da agência de propaganda } & \multirow{2}{*}{ As agências que determinam o plano de mídia } & $\begin{array}{c}\text { "As agências tem rejeição a TV Diário" } \\
\text { Entrevistado } 2\end{array}$ \\
\hline & & & $\begin{array}{c}\text { "A agência define tudo, analisamos as escolhas e } \\
\text { quase sempre acatamos." Entrevistado } 1\end{array}$ \\
\hline & Uso de formatos diferenciados & A importância de se diferenciar & $\begin{array}{c}\text { " Para quebrar a linearidade da comunicação". } \\
\text { Entrevistado } 4\end{array}$ \\
\hline & & & $\begin{array}{c}\text { "Preço é importante , porque a verba é pequena } \\
\text { por loja." Entrevistado } 3\end{array}$ \\
\hline & valor ua minira & Adequaçao ao orçamento & $\begin{array}{c}\text { "Preço tem haver com o que você entrega, é } \\
\text { relativo." Entrevistado } 4\end{array}$ \\
\hline \multirow{9}{*}{$\begin{array}{l}\text { 2. PERCEPÇÃO } \\
\text { SOBRE A TV } \\
\text { DIÁRIO }\end{array}$} & \multirow{4}{*}{ Pontos positivos } & TV de entretenimento & " Tem muito programa musical." Entrevistado 1 \\
\hline & & \multirow{3}{*}{ Ser regional } & $\begin{array}{l}\text { "É interessante a proposta regional da TV Diário, } \\
\text { se tivesse mais verba, investiria" Entrevistado } 3\end{array}$ \\
\hline & & & $\begin{array}{c}\text { " A TV Diário tem petulância em competir com as } \\
\text { outras emissoras". Entrevistado } 2\end{array}$ \\
\hline & & & $\begin{array}{c}\text { " A TV Diário tem uma riqueza cultural } \\
\text { importante." Entrevistado } 4\end{array}$ \\
\hline & \multirow{3}{*}{ pontos negativos } & Atingir público jovem & $\begin{array}{c}\text { "Meu público é jovem a TV Diário não fala com } \\
\text { meu target". Entrevistado } 1\end{array}$ \\
\hline & & Forma de fazer o regionalismo & $\begin{array}{c}\text { " A TV Diário tem uma riqueza cultural } \\
\text { importante, porém as vezes perde a medida do } \\
\text { estereotipo, fica regional só pela linguagem." } \\
\text { Entrevistado } 4\end{array}$ \\
\hline & & Qualidade da programação & $\begin{array}{l}\text { "Tem que melhorar a programação e a forma de } \\
\text { fazer os merchans." Entrevistado } 2\end{array}$ \\
\hline & \multirow{2}{*}{ Atendimento da TV Diário } & clientes anunciantes conhecem & $\begin{array}{l}\text { "Excelente atendimento, visitas relevantes e não } \\
\text { perco tempo". Entrevistado } 4\end{array}$ \\
\hline & & clientes não anunciantes não foram visitados & $\begin{array}{c}\text { "Nunca recebemos visita de alguém da TV } \\
\text { Diário." Entrevistado } 1\end{array}$ \\
\hline \multirow{4}{*}{$\begin{array}{l}\text { 3.CONTEXTO } \\
\text { DIGITAL }\end{array}$} & \multirow{4}{*}{ O impacto comercial do digital na TV aberta } & \multirow{4}{*}{ Investimento } & $\begin{array}{c}\text { "Fazemos internet, mas o carro chefe é TV } \\
\text { Aberta". Entrevistado } 2\end{array}$ \\
\hline & & & $\begin{array}{c}\text { " Em algum momento o investimento em digital } \\
\text { passará a TV Aberta, mas vai demorar." } \\
\text { Entrevistado } 3 \\
\end{array}$ \\
\hline & & & " TV e internet se complementam." Entrevistado 1 \\
\hline & & & " A venda tem que ser unificada." Entrevistado 4 \\
\hline \multirow{2}{*}{$\begin{array}{l}\text { 4. CONTEXTO } \\
\text { POLÍTICO } \\
\text { ECONÔMICO }\end{array}$} & \multirow[b]{2}{*}{ Efeito no valor do investimento } & Aumento de investimento & $\begin{array}{l}\text { " Com mercado retraído precisamos aumentar } \\
\text { nossos investimentos de mídia." Entrevistado } 1\end{array}$ \\
\hline & & Verbas redirecionadas & $\begin{array}{c}\text { " As verbas foram redirecionadas, menos eventos, } \\
\text { mais mídia e a compra de mídia muito bem } \\
\text { planejada." Entrevistado } 3\end{array}$ \\
\hline
\end{tabular}

Fonte: Elaborada pela autora (2018). 
A partir da análise de dados qualitativos, chegamos às seguintes inferências e interpretação dos dados:

1. Relativamente aos "fatores para a escolha dos meios" é possível identificar a preocupação com o retorno do investimento em mídia e o uso das ferramentas técnicas e a importância da TV Aberta para o planejamento de comunicação em todas as entrevistas. Mesmo com uma negociação satisfatória na TV Diário, informação encontrada na pesquisa quantitativa, a análise do custo benefício faz com o cliente seja não anunciante.

2. Quanto ao segundo tema, "percepção sobre a TV Diário", é notório a valorização do regional, porém não suficiente para uma escolha de mídia, pois vários atributos são considerados e o fator audiência tem muito peso.

3. No item relacionado ao "contexto digital" foi unanime a participação de todos em plataformas digitais, tanto com canais próprios, tanto com compra de mídia. Entretanto a TV continua a ser sua mídia de maior investimento e principal foco. Existe a visão de que os dois meios se complementam e um dia a internet poderá superar os investimentos em TV Aberta.

4. Quanto ao quarto tema, "contexto político econômico", houve por parte dos entrevistados um consenso no aumento do investimento para diminuir os efeitos da "crise brasileira" ou ainda adequação dos investimentos de marketing para priorizar a compra de mídia.

\section{CONSIDERAÇÕES}

De uma forma geral e a partir dos dados encontrados percebemos que a TV Aberta é um dos principais meios que os anunciantes usam e acreditam para atingir seus objetivos de marketing. A convergência digital entre TV e Internet é entendida como absorvida pelos meios e sem comprometimento de cada um deles. Outro fato importante é o uso de ferramentas técnicas, como GRP, C P M, análise de audiência e a marcante preocupação com o retorno do investimento em mídia. Esse fato mostra um amadurecimento do mercado e da disseminação de práticas profissionais mais aprimoradas e divulgadas por meios e profissionais.

Os anunciantes entendem e se sentem atraídos pelo apelo regional e por formatações diferenciadas, esta última deve estar ajustada ao investimento do anunciante.

Quanto ao atendimento dos clientes pelo agenciador de propaganda ficou claro a importância da preparação desses executivos de venda, quanto a informação sobre o veículo 
que negocia e sobre o negócio do anunciante e seu mercado. A Crise econômica e política no Brasil em alguns segmentos incentivou o aumento de consumo de compra de mídia, para com isso neutralizar a inércia do consumidor por conta do seu estado de insegurança no cenário atual.

Analisando sob a perspectiva da TV Diário alguns itens evidenciados dizem respeito a vários itens, dentre eles a necessidade de a emissora investir em médios e grandes clientes, pois essa é a fatia de não anunciantes presentes em não anunciantes e na TV Diário existe a concentração de clientes pequenos.

Outro item é o relacionamento com agências de propaganda do mercado de Fortaleza, foi observado que os não anunciantes têm concentrado sua compra por meio desse canal de compra. Na pesquisa qualitativa foi notória a fala da participação efetiva das decisões ou sugestão de mídia por parte das agências.

Um fator que exige uma grande atenção por parte da TV Diário é com relação aos agenciadores de propaganda, os clientes não anunciantes não são visitados por profissionais da TV Diário e o contraponto dessa situação é o quanto demonstram satisfação os clientes que são atendidos por executivos de vendas da TV Diário.

O regionalismo é bem recebido pelos anunciantes, porém não pode ser só na linguagem e a programação de forma geral precisa fazer uma leitura cultural, social e econômica das potencialidades do Ceará. Ainda sobre a programação é visto como um grande esforço o que a TV Dário produz hoje. A interação digital deve ser pauta da emissora, pois na visão dos anunciantes e não anunciantes essa convergência é salutar e bem presente.

Os formatos diferenciados são entendidos como relevantes, precisam ter uma melhor execução, conforme fala dos anunciantes, pois são um grande produto para a TV Diário. Nesse contexto a presença dos apresentadores aparece como um fator importante para a compra de mídia e esses profissionais precisam ser mais divulgados e integrados a comercialização dos espaços.

\section{REFERÊNCIAS}

ACERT. Associação Cearense de Emissoras de Rádio e Televisão. Disponível em: <http://acert.org.br/pdf/guia.pdf>. Acesso em: 1 maio 2018.

BRASIL. Presidência da República. Pesquisa brasileira de mídia 2016: hábitos de consumo de mídia pela população brasileira. Brasília: Secom, 2016. 
CANATTA, F. Tv e segunda tela: uma análise do horário nobre no Twitter. 2014. Dissertação (Mestrado em Comunicação Social) - Pontifícia Universidade Católica do Rio Grande do Sul, Rio grande do Sul 2014.

CETIC. Centro Regional de Estudos para o Desenvolvimento da Sociedade da Informação. Domicílios sem acesso à internet, por motivos para a falta da internet. Disponível em: <https://cetic.br/tics/domicilios/2017/domicilios/A10/>. Acesso em: $1^{\circ}$ jul 2018.

CENP. Conselho Executivo das Normas padrões. Normas-Padrão da Atividade Publicitária. Disponível em: <http://www.cenp.com.br/documento/normas-padraoportugues $>$. Acesso em: 18 mar. 2018.

DEMARCHI, C. H. A legislação da TV aberta no Brasil: regulação e democratização. Quórum Académico, v. 14, n. 2, p. 122-137, 2017.

DUARTE, J.; BARROS, A. (Org.). Métodos e Técnicas de Pesquisa em Comunicação. 2. ed. São Paulo: Atlas, 2011.

GRUPO DE MÍDIA DE SÃO PAULO. Mídia Dados 2018. Disponível em: https://www.gm.org.br/midiadados. Acesso em: 12 jul. 2018.

HONÓRIO, E.; MORENO, D. (Orgs.). Airton Queiroz: destino \& trajetória. Fortaleza: Universidade de Fortaleza, 2015.

JAFFE, J. O Declínio da Mídia de Massa - Por que os comerciais de TV de 30 segundos estão com os dias contados. São Paulo: M Books do Brasil Editora Ltda, 2008.

JENKINS, H. Cultura da convergência. São Paulo: Aleph, 2009.

KANTAR IBOPE MEDIA. Internautas brasileiros assistem TV e navegam na internet ao mesmo tempo. Disponível em: <http://www.ibope.com.br/pt-br/noticias/Paginas/88-dosinternautas-brasileiros-assistem-TV-e-navegam-na-internet-ao-mesmo-tempo-.aspx >. Acesso em: 2 nov. 2016.

Investimento publicitário $\mathbf{1}^{\mathbf{0}}$ semestre de 2017. Disponível em:

$<$ https://www.kantaribopemedia.com/investimento-publicitario-1o-semestre-2017/ Acesso em: 22 dez. 2017.

KOTLER, P. Administração de Marketing: a edição do novo milênio. São Paulo: Prentice Hall, 2000.

KOTLER, P.; KARTAJAYA, H.; SETIAWAN, I. Marketing 3.0: as forças que estão definindo o novo marketing centrado no ser humano. São Paulo: Elsevier Brasil, 2010

LUPETTI, M. Administração em Publicidade. São Paulo: Cengage Learning, 2014.

SISSORS, J. Z.; BUMBA, L. Planejamento de mídia. São Paulo: Nobel, 2001. 
SHAVER, M. A. Como vender a mídia: o marketing como ferramenta de venda do espaço publicitário. São Paulo: Nobel, 2002.

SMITH, K. T. Digital marketing strategies that Millennials find appealing, motivating, or just annoying. Journal of Strategic Marketing, v. 19, p. 489-499, Oct. 2011.

TAMANAHA, P. Planejamento de Mídia: Teoria e Experiência. 2. ed. São Paulo: Pearson, 2011.

TV DIÁRIO. Disponível em: <http://tvdiario.verdesmares.com.br/institucional/tv-diario-evoce>. Acesso em: 2 nov. 2016.

VERGARA, S. C. Métodos de coleta de dados no campo. 2. ed. São Paulo: Atlas, 2012.

YIN, R. K. Estudo de caso - planejamento e métodos. 4. ed. Porto Alegre: Bookman, 2010.

WOLFF, M. Televisão é a nova televisão. São Paulo: Globo Livros, 2015

Original recebido em: 25 de janeiro de 2019

Aceito para publicação em: 24 de maio de 2019

Lucinda Maria Martins Tavares

Mestra em Administração com ênfase em comunicação. Especialista em Marketing pela UNIFOR - CE (1992). Especialista em Comunicação Social - Propaganda pela Universidade de Fortaleza (1997). Especialista em negócios pelo IBMEC -RJ (2003). Professora da Universidade de Fortaleza, atuando nas áreas de mídia e marketing. Atuando no mercado publicitário cearense há mais de 25 anos, como gestora comercial/marketing nos grandes grupos de Comunicação como Sistema Verdes Mares, Sistema Jangadeiro e Grupo O POVO de Comunicação

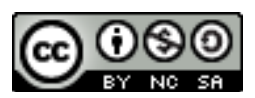

Esta obra está licenciada com uma Licença

Creative Commons Atribuição-NãoComercial-CompartilhaIgual 4.0 Internacional 